\title{
OS PRODUTOS DA ECONOMIA SOLIDÁRIA: EXEMPLOS DA BUSCA DA SUSTENTABILIDADE ECONÔMICA, SOCIAL E AMBIENTAL
}

\author{
Silvia Aparecida Guarnieri Ortigoza ${ }^{*}$
}

\begin{abstract}
RESUMO
A Economia Solidária define-se por princípios que prezam pela justiça social, ressaltando o humano e o coletivo. Ela apresenta diversas alterações nas relações sociais e produtivas que passam a estar centradas na autogestão, cooperação e solidariedade. Este artigo aborda os significados dos produtos provenientes da economia solidária, procurando refletir sobre os limites e as possibilidades que apresentam para incorporar práticas sustentáveis do ponto de vista ambiental, mas, também de permitir a sustentabilidade econômica e social. Serão destacadas as pesquisas sobre Economia Solidária realizadas pelo Laboratório de Estudo Territoriais (LAET), do Departamento de Geografia da UNESP para subsidiar algumas atividades produtivas que estão sendo desenvolvidas em Rio Claro (SP). A Economia Solidária tem possibilitado a inclusão produtiva de muitas famílias na cidade de Rio Claro e, levado a melhoria das condições gerais de vida, diminuindo as desigualdades em âmbito municipal. Este novo caminho econômico representa uma alternativa viável que permite integrar seus produtos aos qualitativos dos diferentes territórios, considerando às potencialidades das comunidades e valorizando a cultura e a identidade local.
\end{abstract}

Palavras-chave: Território. Economia solidária. Produção. Sustentabilidade. Justiça social.

\section{INTRODUÇÃO}

As economias locais, regionais, nacionais e globais têm apresentado crises consecutivas, o que tem impactado os diferentes territórios. As reestruturações organizacionais e produtivas foram sendo necessárias para encontrar novos caminhos para manter a vitalidade das empresas capitalistas, mas, a redução dos postos de empregos continuou, e, somado a isso, foi se expandindo o subemprego, o trabalho precário e o trabalho informal. A Economia Solidária brasileira entra neste contexto econômico de forma mais intensificada a partir dos anos de 1990, e, cada vez mais, vem se firmando como um caminho alternativo para driblar essas crises consecutivas que afetam de forma mais direta os trabalhadores.

A formação de redes de colaboração solidária tem sido uma prática bastante relevante que tem ampliado as condições de produção e comercialização dos produtos provenientes da Economia Solidária, essas questões foram muito bem debatidas por Mance (1999, 2002).

\footnotetext{
*Doutora em Geografia pela Universidade Estadual Paulista (UNESP). Professora do departamento de Geografia da UNESP. E-mail: sago@rc.unesp.br
} 
Aos poucos essa economia alternativa vai substituindo por cooperação e solidariedade o comportamento centrado em valores capitalistas, tais como: a concorrência, a competitividade, o individualismo. Essas substituições não atingem todas as esferas da economia e nem envolvem todos os trabalhadores. Neste processo, são favorecidas, justamente, aquelas pessoas que se encontram em extrema pobreza, sem perspectivas de emprego e renda, e que, muitas vezes, estão dependentes de políticas afirmativas do Estado.

De fato, por não ser tão abrangente, a Economia Solidária não representa a grande saída para as crises do capitalismo, mas tem, nos últimos anos, se apresentado como uma possibilidade real de inserir diversas pessoas no mundo produtivo, com novos princípios e novas relações produtivas e de trabalho.

Mas, além de buscar a sustentabilidade econômica e social para milhares de pessoas no Brasil e criar mecanismos de sobrevivência por meio do trabalho e não do emprego, a Economia Solidária também apresenta outros desafios, vinculados à questão ambiental. Nesta economia, não basta que as pessoas encontrem formas de sobrevivência se inserindo num mundo produtivo solidário, é preciso que em todas as etapas da produção de seus produtos e serviços haja uma preocupação com a preservação ambiental, com o consumo consciente e ético e, principalmente, com a diminuição do desperdício, entre outros.

Sobre a questão do consumo, especificamente, é importante constatar que vem ocorrendo vários debates no plano teórico criando diversos termos para demonstrar as transformações que vêm ocorrendo no mundo atual, destacamos o consumo sustentável, consumo responsável, consumo alternativo, consumo ético, mas existem muitos outros. Sobre o consumo ético, Fretel e SimoncelliBourque (2003) colocam que, ele visa incorporar a dimensão ética na atividade de consumo e consiste em consumir bens e serviços "socialmente justo e ambientalmente sustentável que respeita a cultura e promove uma melhor qualidade individual e social de vida". (p. 48).

Todavia, mais do que refletir teoricamente sobre as novas modalidades de consumo, é preciso reconhecer que ele vem sendo realmente transformado, pois na Economia Solidária as práticas de produção e comercialização já revelam esses novos comportamentos de consumo.

Em outras palavras, a Economia Solidária, em todas as suas etapas, desde a produção até o pósconsumo, tem como meta a busca pelos diferentes níveis de sustentabilidade: a econômica, a social e a ambiental.

ra, se é possível estabelecer e criar relações amplamente capitalistas, também é possível criar mecanismos para despertar novos rituais e nova moral que tenham como conteúdo relações solidárias. Esse conjunto de novas possibilidades se apresenta nas brechas residuais deixadas pelo próprio capitalismo. O grande esforço é transformar essas virtualidades em novas práticas sociais. (ORTIGOZA, 2013, p. 41). 
No Brasil, já é possível verificar nas diversas experiências municipais, que a Economia Solidária vem apresentando importantes mudanças comportamentais que podem transformar-se em resultados concretos de relações de produção mais sustentáveis.

Devido às grandes diferenças regionais, o Brasil apresenta diversas experiências territoriais em Economia Solidária, as quais se multiplicaram a partir de 2003 com a criação da Secretaria Nacional de Economia Solidária (SENAES) vinculada ao Ministério do Trabalho e Emprego, que passou a incentivar e financiar projetos e programas municipais. Neste artigo, iremos enfatizar as experiências em Economia Solidária no município de Rio Claro, localizado no estado de São Paulo.

\section{PRINCIPAIS AVANÇOS E DESAFIOS DA ECONOMIA SOLIDÁRIA EM UMA CIDADE MÉDIA PAULISTA}

O município de Rio Claro apresentava em 2010, segundo o IBGE, uma População Urbana de 181.720 habitantes e uma População Rural de 4.533 habitantes. Trata-se de uma típica cidade média paulista que está localizada a aproximadamente $170 \mathrm{Km}$ de distância da metrópole de São Paulo e a $90 \mathrm{Km}$ da Região Metropolitana de Campinas. O seu entorno reúne importantes cidades com grande incremento industrial e um moderno setor terciário, essa área destaca-se como um importante eixo de desenvolvimento do estado de São Paulo, pois está interligada por excelentes rodovias capazes de integrar outros estados e regiões brasileiras. Mas, mesmo com todos esses qualitativos logísticos e econômicos, Rio Claro não tem conseguido atender a demanda por emprego e renda de sua população e, com isso, tem aumentado de forma significativa, nos últimos anos, a pobreza, a exclusão social, a marginalidade e a violência.

O poder público municipal, não poderia continuar vendo a exclusão social aumentando, ano a ano e, desse modo, foram criadas algumas ações a partir da Secretaria Municipal de Assistência Social que visavam a criação de mecanismos para propiciar oportunidades de trabalho e renda para a população que mais necessitava. Essas ações, desde o início, contaram com a parceria de pesquisadores/geógrafos e alunos da UNESP.

Neste processo, a primeira grande ação foi no ano de 2010, quando foram criadas as condições para implantação do Programa de Economia Solidária de Rio Claro (SP).

A criação do referido Programa teve como embasamento a identificação e localização dos sujeitos mais necessitados, bem como o mapeamento dos territórios urbanos procurando demonstrar as condições de vida e a vulnerabilidade social na cidade. O livro intitulado "Desfazendo os nós do Capital: território, ação social e economia solidária" traz os resultados parciais desta primeira fase 
das pesquisas relacionadas ao referido Programa ( CORTEZ; MENDES; ORTIGOZA, 2013).

Outra ação fundamental foi a aprovação da Lei 4.036 de 8 de março de 2010, que veio legitimar a Política Pública de Economia Solidária no município de Rio Claro e dar as condições de funcionamento do Centro Público de Economia Solidária. O referido centro tem a função de articular os envolvidos na Economia Solidária e de abrigar a Incubadora Popular e o Ponto Fixo de comercialização dos produtos.

A partir deste marco legal e do Centro Público, muitas outras ações foram ocorrendo, entre elas destaca-se a criação do Fórum Municipal de Economia Solidária que foi garantindo uma efetiva participação popular e, hoje, já pode ser considerado um importante instrumento democrático. Os cidadãos têm voz e isso faz com que todas as prioridades do movimento social de economia solidária sejam consideradas e, dessa forma, as mobilizações ganham força o que repercute diretamente no fortalecimento da Economia Solidária no município.

Os fóruns também têm se convertido em um instrumento de divulgação da Economia Solidária, pois, durante as reuniões, é facilmente observável o aumento do público e a adesão de novos grupos de pessoas interessados neste outro caminho econômico. Os participantes passam a compreender os processos de trabalho na perspectiva da solidariedade, do cooperativismo e da autogestão.

A instituição do Conselho Municipal de Economia Solidária foi também uma outra conquista importante, pois vem dando agilidade nas políticas públicas deliberando sobre diversos assuntos relacionados com a Economia Solidária local. Entretanto, foi no ano de 2014 que a Economia Solidária mais avançou em Rio Claro, pois foram realizadas a Pré-Conferência e a I Conferência Municipal de Economia Solidária, seguindo todas as diretrizes da SENAES. Ambas as conferências foram responsáveis por abordar, por meio da participação popular, as principais fragilidades e potencialidades do município, indicando quais seriam as prioridades de ações para os próximos três anos.

Observa-se que essas práticas assentadas na participação popular são um exercício da cidadania, é o que aponta o trecho que segue:

Participar de uma cooperativa ou forma econômica solidária é uma experiência que pode educar para a prática e para o exercício consciente de direitos e deveres políticos - por intermédio das decisões tomadas coletivamente em assembleias ou por representantes eleitos democraticamente, da fiscalização coletiva das contas, da transparência das informações, da garantida de igualdade de voz e voto a todos os integrantes. Mais ainda, é experiência que pode restaurar condições de sociabilidade (ameaçadas sobretudo em situações extremas de marginalização econômica), à medida em que resgata o senso de pertencimento a uma coletividade, fortalece laços de confiança e respeito mútuos, aumenta o reconhecimento da alteridade, e no plano pessoal, promovo a capacidade de expressão a auto-estima e 
a existência de projetos de vida. Quando suas características políticas são exercidas de forma plena, a economia solidária chama atenção para a importância da participação ativa em processos coletivos e pode contribuir para fortalecer a cidadania e promover a dimensão substantiva da democracia. (CUNHA, 2003, p. 47-48).

Os resultados das conferências realizadas em Rio Claro corroboram com o pensamento de Cunha (2003), pois retratam que a Economia Solidária vem despertando nas pessoas uma vontade enorme de buscar mudanças positivas em suas vidas e que o caminho é a participação, o trabalho e a solidariedade. Todos os apontamentos realizados durante essas conferências municipais foram apresentados pelos representantes eleitos pelo Fórum de Economia Solidária, na Conferência Estadual, e muitas das metas apontadas em Rio Claro acabaram sendo destacadas também na Conferência Nacional de Economia Solidária.

Além disso, as prioridades e estratégias debatidas nas conferências serviram de base para a formulação do I Plano Municipal de Economia Solidária de Rio Claro, que foi entregue ao Prefeito Municipal em dezembro de 2014, sua aprovação ocorreu por meio de audiência pública e, cabe ressaltar que, durante todas as etapas da elaboração do Plano houve a participação popular.

Este breve histórico sobre a Economia Solidária em Rio Claro teve o objetivo de demonstrar que essas transformações não foram fáceis ou rápidas de serem conquistadas, mas, o mais importante é ter vontade de lutar contra a economia globalizada e perversa que vem tornando, cada vez mais desigual, as condições de vida da população brasileira. A Economia Solidária teve vários percalços em Rio Claro, pois se orientava de forma muito dependente da vontade política e, portanto, passou por vários avanços, rupturas e descontinuidades. Nos últimos sete anos, os atores populares ganharam força e as políticas públicas e ações foram intensificadas e, assim, já são visíveis alguns benefícios efetivos para a população.

Atualmente, existem, em Rio Claro, algumas experiências de Empreendimentos Econômicos Solidários(EES) que, integrados aos pesquisadores da UNESP, a outros órgãos de fomento e aos gestores públicos, já têm demonstrado alguns resultados bastante positivos na busca pela sustentabilidade.

Dentre as experiências positivas de EES de Rio Claro, destacaremos a seguir dois exemplos, o primeiro é o EES "Biojoias - Joias da Terra" e o segundo é a "Cooperativa de Trabalho dos Catadores de Material Reaproveitável -COOPERVIVA”.

\subsection{Biojoias - Joias da Terra}

As Joias da Terra são produtos solidários. Além desse qualitativo, as Joias da Terra têm feito 
sucesso na cidade de Rio Claro e na região, por serem identificadas como produtos sustentáveis. Foram ganhando, aos poucos, grande visibilidade e, por isso, têm conseguido garantir renda para as famílias envolvidas.

Biojoias é nome dado ao EES responsável pela produção das Joias da Terra. Este EES tem buscado para todos os seus produtos uma identificação "solidária e sustentável", desse modo em todo o processo de produção das joias/bijuterias as relações sociais e produtivas estão centradas nos princípios da economia solidária e em posturas ecologicamente corretas. Toda a matéria prima dos produtos é rejeito da natureza, ou seja, são cascas de árvores, sementes, folhas secas, que se encontram caídas no chão. Primeiramente são realizadas as coletas seletivas dos resíduos das árvores e, posteriormente, levadas para as artesãs criarem colares brincos, pulseira e artesanatos utilizando-se daqueles materiais coletados. (Figura 1)

Observa-se durante todo o processo de produção das Joias da Terra a importância da criatividade e do conhecimento tácito que, de forma natural, acabam valorizando a cultura e as experiências cotidianas. Na Economia Solidária a produção é desenvolvida de forma a manter uma intima ligação com a vida social e com o território.

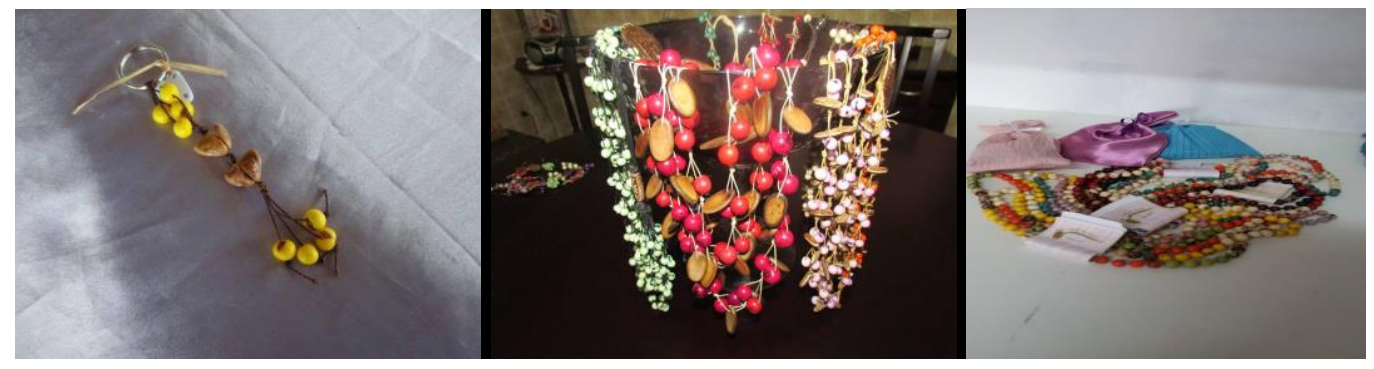

Figura 1: Joias da Terra - Biojoias

Fonte: https://www.facebook.com/groups/140454076128501/?fref=ts

No EES Biojoias durante a produção todos os envolvidos são responsáveis por atividades planejadas de forma conjunta, a solidariedade impera e a relação patrão-empregado é totalmente rompida. A autogestão e a cooperação, por sua vez, aparecem com toda força, durante a coleta, produção e a comercialização. (Figura 2) 


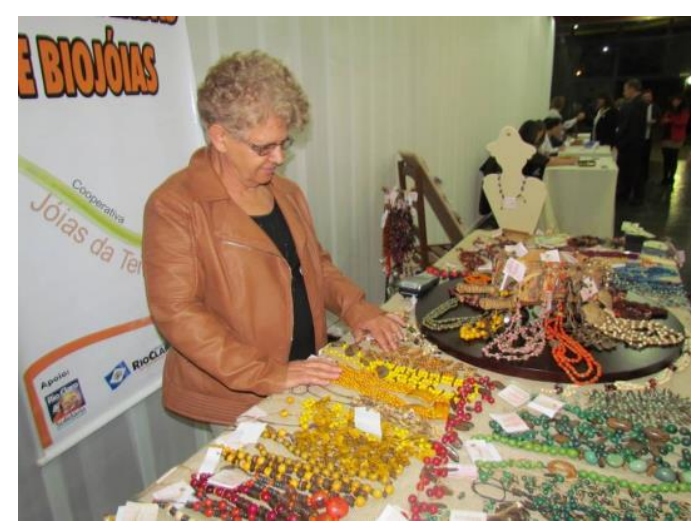

Figura 2: Artesã e produtos do Empreendimento Econômico Solidário - Biojoias

Fonte: https://www.facebook.com/groups/140454076128501/?fref=ts

Este é um exemplo simples, mas muito educativo que ajuda a exemplificar que a economia solidária pode acontecer. A Biojóias é, portanto, um exemplo que nos permite reafirmar a ideia de Paul Singer de que "uma outra economia é possível”.

No trecho que segue o referido autor declara seu entusiasmo por essa nova alternativa econômica e de produção que se apresenta e ganha força no mundo atual.

A construção de um modo de produção alternativo ao capitalismo no Brasil ainda está no começo, mas passos cruciais já foram dados, etapas vitais foram vencidas. Suas dimensões ainda são modestas diante do tamanho do país e de sua população. Mesmo assim, não há como olvidar que dezenas de milhares de pessoas já se libertaram pela solidariedade. O resgate da dignidade humana, do respeito próprio e da cidadania destas mulheres e destes homens já justifica todo esforço investido na economia solidária. É por isso que ela desperta entusiasmo (Singer, 2002, p.127).

Além do econômico, o EES Biojoias é uma referência do exercício da cidadania e de uma luta digna, por meio do trabalho, na busca pela justiça social.

\subsection{Cooperviva: Cooperativa de Trabalho dos Catadores de Material Reaproveitável}

Um outro grande exemplo positivo das experiências em Economia Solidária de Rio Claro é a COOPERVIVA, que faz parte do Programa de Economia Solidária e que tem realizado a coleta seletiva no município e, portanto, tem possibilitado o aproveitamento de materiais recicláveis, que antes eram depositados nos aterros sanitários.

Esta cooperativa representa possibilidades e alternativas de trabalho e renda para a parcela da população mais vulnerável da cidade de Rio Claro e tem suas atividades fundamentadas em legislações específicas para o setor. 
Em seu Estatuto consta que a cooperativa "tem como finalidade social a congregação de profissionais que tenham sua atividade voltada para a coleta seletiva de material reaproveitável". No mesmo documento ainda consta que a COOPERVIVA tem "por objetivo principal proporcionar o exercício e o aprimoramento da atividade profissional dos associados, com base na colaboração recíproca, visando sua defesa econômica e social e proporcionando-lhes condições para o exercício de suas atividades". As atividades que estão destacadas no documento são: coleta, triagem, beneficiamento, prestação de serviços e comercialização. (ESTATUTO DA COOPERVIVA, 2001).

A COOPERVIVA foi criada em 2002 e funcionava em uma área cedida pela Prefeitura através de um Decreto Municipal, na ocasião participavam 30 cooperados. A partir de 2011 ela teve uma expansão bastante considerável, devido à nova área que passou a ocupar que é muito maior que a antiga, mas que também é cedida pela Prefeitura, além disso o número de cooperados praticamente dobrou. Essa expansão também se deve ao aumento do número de bairros atendidos pela coleta seletiva realizada pela COOPERVIVA, em 2012, $70 \%$ da área urbana do município era atendida, e no ano de 2014 a coleta atingiu $100 \%$ da cidade.

Além da parceria com a Prefeitura e com a UNESP, a COOPERVIVA tem projetos com a Tetra Pak e o Compromisso Empresarial para a Reciclagem (CEMPRE), esses tipos de integração por meio de programas especiais tem propiciado doações de equipamentos que facilitam e agilizam os trabalhos. Além disso, várias capacitações são realizadas as quais favorecem diretamente as competências para a realização de práticas de trabalho mais sustentáveis e saudáveis entre os cooperados.

Em 2013, a COOPERVIVA tomou posse de uma esteira de separação, que foi conquistada por meio do Projeto aprovado pela SENAES (Edital 003), este equipamento agiliza o transporte de resíduos sólidos, proporcionando uma triagem mais rápida dos materiais. Além disso, a esteira melhorou a qualidade de vida dos trabalhadores, a partir do momento que, em menor tempo e com menos esforço, conseguem selecionar mais materiais. (Figura 3). 


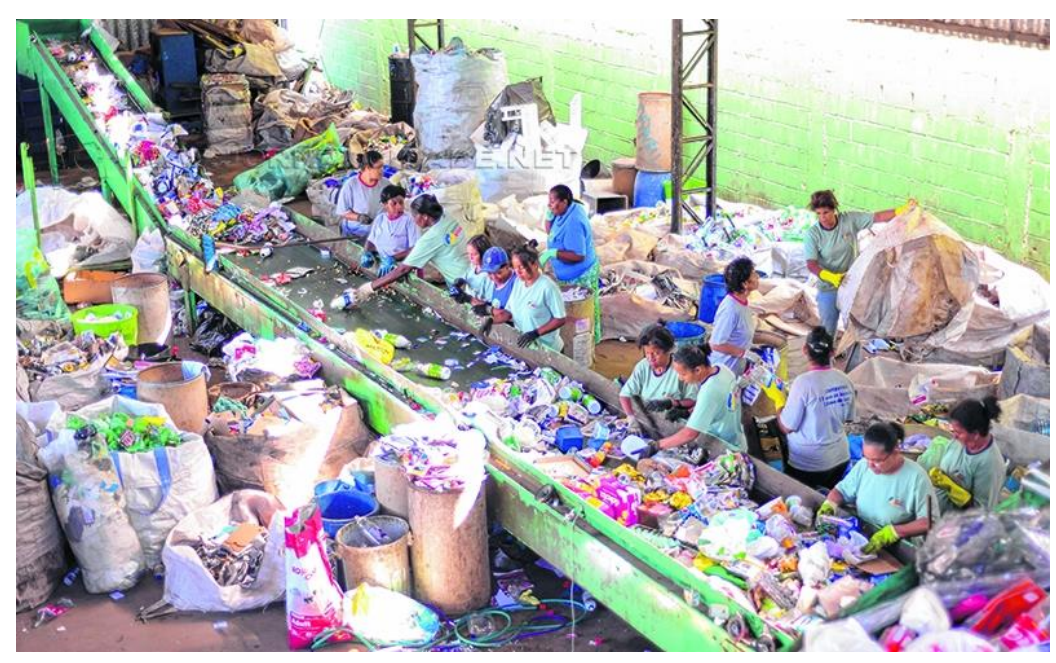

Figura 3: Separação do lixo reciclável executada pela COOPERVIVA

Fonte: http://www.jornalcidade.net/ - data: 8 jun, 2015

Em um artigo sobre a referida Cooperativa, Lima (2013) detalha, um pouco mais, sobre os tipos de materiais envolvidos nas atividades realizadas pelos trabalhadores.

A cooperativa trabalha com materiais recicláveis separados nas categorias: papel (papel, jornal, papel revista, papel branco, papelão e embalagens Tetra Pak), plástico (PET, PEAD, PEBD, PVC, OS e PP), metal (cobre, alumínio, e sucata de ferro) e vidro (vidro escuro e vidro branco). Alguns materiais que não sofrem transformação são apenas coletados, separados e enfardados. Outros são vendidos e reutilizado por terceiros, como, por exemplo, as garrafas PET, reutilizadas para produtos de limpeza, e os vidros de conservas, reutilizados no artesanato. (LIMA, 2013, p.162-163)

Atualmente, novas perspectivas se abrem para a COOPERVIVA, entre elas destaca-se iniciativas de comercializações de produtos encontrados durante a triagem e que apresentam condições de reuso. Para tanto, está sendo criada uma Loja Sustentável para expor esses produtos que, mesmo vindos do lixo, ainda podem ser de utilidade para muitas pessoas. A COOPERVIVA também manterá uma barraca na Feira de Economia Solidária de Rio Claro. Essas novas atividades comerciais agregam ainda mais os valores ambientais e solidários, pois fará despertar na população rio-clarense o consumo consciente, ético e sustentável.

Os catadores ligados a cooperativas e mesmo aqueles em situações de informalidade realizam um importante serviço de utilidade pública, pois fazem com que haja a reinserção do lixo no ciclo produtivo gerando diversos benefícios positivos e economia de recurso naturais, beneficiando toda a sociedade. Assim, quem realiza este tipo de trabalho tem que ser muito valorizado, pois são atores que contribuem com a conservação do ambiente, minimizando sua degradação. 
A experiência da COOPERVIVA demonstra que, embora ainda existam diversos desafios a serem superados a importância desses trabalhadores para o município de Rio Claro é inquestionável. Todos os trabalhadores envolvidos nesta cooperativa têm a consciência da importância de suas atividades tanto para o meio ambiente, já que os resíduos recolhidos são transformados em matériaprima diminuindo o consumo de recursos naturais, como também para eles próprios, pois esse trabalho sustentável e solidário volta em forma de renda e garante o sustento de suas famílias. Assim, nas diferentes dimensões, a econômica, a ambiental e a social, esses trabalhadores são vitoriosos.

\section{CONSIDERAÇÕES FINAIS}

Os movimentos sociais em economia solidária acabaram ganhando força no Brasil unindo pessoas que lutam por seus direitos de trabalho e renda. França Filho (2006) é um grande estudioso da Economia Solidária inserindo-a dentro do contexto dos movimentos sociais brasileiros. De fato, a Economia Solidária no município destacado neste artigo, pode perfeitamente ser abordada como um movimento social, pois foi capaz de unir diferentes dilemas compondo redes de ajuda mútua e, por meio da prática participativa e atuante, diversas pessoas acabaram ganhando representação política e, assim, puderam dentro desse movimento contribuir com a implantação de políticas públicas municipais.

Em síntese, foi em torno de práticas participativas e reivindicatórias que conquistaram algumas soluções para a inclusão produtiva. Neste sentido, Santos (2010), acreditando que um novo mundo é possível, já nos colocava que: "Esse mundo novo anunciado não será uma construção de cima para baixo, como a que estamos hoje assistindo e deplorando, mas uma edificação cuja trajetória vai se dar de baixo para cima. “( (p. 170)

Notadamente, a grande força da Economia Solidária em Rio Claro, tem sido a de manter a identidade dos produtos com as pessoas que os produzem, vinculando também essas pessoas com os territórios onde vivem. Assim a produção e os produtos passam a ser bastante heterogêneos, diferentemente da força homogeneizadora dos produtos e dos gostos amplamente utilizada pela produção capitalista. Essa questão corrobora com o que nos adverte Santos (2006, p.313) “(...) temos o direito a ser iguais sempre que a diferença nos inferioriza; temos o direito de ser diferentes sempre que a igualdade nos descaracteriza."

Atualmente, em Rio Claro, a Economia Solidária encontra-se territorialmente articulada, mas muitos outros desafios se apresentam, tais como: a) ampliar o alcance do Programa de Economia Solidária, pois ainda existem muitas famílias em extrema pobreza e dependentes das 
ações afirmativas do governo federal; b) abrigar no processo de incubação os EES que de fato necessitem de orientações em seus processos de produção para que a busca pela sustentabilidade permaneça como identidade dos produtos; c) criar estratégias comerciais permanentes (feiras e pontos fixos) que sejam capazes de fazer circular os produtos provenientes da Economia Solidária, valorizando-os de forma a divulgar seus vínculos com o território.

O importante é destacar que a Economia Solidária, como vem sendo desenvolvida em Rio Claro e no Brasil de forma geral, têm permitido aos envolvidos a conquista de condições de vida e de trabalho menos exploratórias, valorizando o bem viver. Podemos, pelas diversas experiências que temos observado, destacar que tem prevalecido o coletivo nos processos de tomada de decisão; a justiça na produção e na comercialização. A própria conscientização do consumidor no que tange à sustentabilidade ambiental e social vem sendo despertada, comportamentos esses que há algum tempo eram tidos como utopia.

Em outra ocasião, Ortigoza (2014, p. 255) destaca que "a ação política em economia solidária prevê uma produção emancipatória, onde existe a possibilidade de se conhecer e dominar todo o ciclo de produção das mercadorias, o que contribui com a superação de parte das contradições entre capital e trabalho." Isso se torna possível, pois "não existe a separação entre os que detêm os meios de produção e os que detêm a força de trabalho e, assim, a relação patrãoempregado é eliminada, possibilitando a apropriação coletiva da riqueza produzida.”

Gaiger (2003) é um outro autor que tem elaborado uma reflexão aprofundada sobre a Economia Solidária diante do modo de produção capitalista, e defende os princípios da auto-gestão como o grande caminho para driblar os efeitos perversos do capitalismo globalizado.

Temos diversas possibilidades de avanços na Economia Solidária no Brasil, o governo federal tem contribuído muito por meio da SENAES com incentivos financeiros de projetos e programas municipais e também estabelecendo as diretrizes centrais do processo de desenvolvimento social, econômico e territorial. Entretanto, são as práticas que se realizam na esfera local (comunidade, bairro, município) que demonstram as transformações necessárias e seus limites. Portanto, quanto mais forem levadas em conta a diversidade cultural, a identidade local e as experiências cotidianas das diferentes comunidades, mais chances de sucesso. Dito de outro modo, não adianta criar "modelos" e "manuais" com verdadeiras "receitas" de como agir em Economia Solidária, pois a realidade socioespacial é que norteará as possibilidades e os limites de seu desenvolvimento. 


\section{REFERÊNCIAS}

CUNHA, G. C. Dimensões da luta política nas práticas de economia solidária. In Uma outra economia é possível: Paul Singer e a economia solidária. A.R. Souza, G. C. Cunha and R. Y. Dakuzaku (orgs.). São Paulo: Contexto. 2003, 45-72.

FRANÇA FILHO, G. C. Economia Solidária e movimentos sociais. In: MEDEIROS, A. et al. Políticas públicas de Economia Solidária: por um outro desenvolvimento. . Recife: Editora Universitária da UFPE. 2006. 49-92.

FRETEL, A. C; SIMONCELLI-BOURQUE, E. O comércio justo e o consumo ético. Rio de Janeiro: DP\&A: Fase, 2003.

GAIGER, L. I. () A economia solidária diante do modo de produção capitalista. Caderno CRH, Salvador, n. 39, jul./dez. 2003. 181-211.

LIMA, V. S. O papel do cooperativismo na economia solidária: o caso da COOPERVIVA de Rio Claro/SP. In: MENDES, A. A.; CORTEZ, A. T. C.; ORTIGOZA, S. A. G. (orgs). Desfazendo os nós do capital - território, ação social e economia solidária. Bauru, SP: Canal 6. 2013.

MANCE, E. A. Redes de colaboração solidária: Aspectos econômicos-filosóficos: complexidade e libertação. Petrópolis: Vozes. 2002.

A revolução das redes: A colaboração solidária como alternativa pós-capitalista à globalização atual. Petropolis: Vozes. 1999.

MENDES, A. A.; CORTEZ, A. T. C.; ORTIGOZA, S. A. G. (orgs). Desfazendo os nós do capital : território, ação social e economia solidária. Bauru, SP: Canal 6. 2013.

ORTIGOZA, S. A. G. Vamos privilegiar os mais fracos: a economia solidária brasileira como possibilidade de (re)inserção do território como base do desenvolvimento. Revista GOT, n. ${ }^{\circ}$ 6, Revista de Geografia e Ordenamento do Território (dezembro de 2014): Porto (PT), p. 241-257.

SANTOS, B. S. A gramática do tempo: para uma nova cultura política. S. Paulo, Porto: Cortez Ed., Afrontamento. 2006.

SANTOS, M. Por uma outra globalização: do pensamento único à consciência universal. Rio de Janeiro: Record. 2010.

SINGER, P. A recente ressurreição da economia solidária no Brasil. Santos, B. S. (org.) Produzir para viver: os caminhos da produção não capitalista. Rio de Janeiro: Civilização Brasileira. 2002. 